\title{
Need for Speed in the Sharing Economy: How IT capability drives Innovation Speed?
}

\author{
Wooje Cho \\ Seoul National University \\ woojecho@snu.ac.kr \\ Prasanna Karhade \\ University of Hawaii Manoa \\ karhade@hawaii.edu
}

\author{
Ojaswi Malik \\ The University of Hong Kong \\ ojaswim@connect.hku.hk \\ Abhishek Kathuria \\ Indian School of Business \\ abhishek_kathuria@isb.edu
}

\begin{abstract}
Though innovation is considered to be the lifeblood of business, speed of innovation is more critical than innovation itself. IT plays a critical role in the process of open innovation as it is based upon collaborating with suppliers and customers. IT enables increased collaboration and generation of insights across the firm's partner network. We examine the role of IT-enabled capabilities in determining the speed of innovation. We hypothesize that collaboration with customers is more effective than collaboration with suppliers for firms to speedily innovate. Further, a firm's digital collaboration with customers is more effective when Business Intelligence systems are used. Econometric analyses of data from 249 U.S. firms yields strong support for our hypotheses. While both customer-side and supplierside digital collaboration are positively associated with innovation speed, the effect of customer-side digital collaboration on innovation speed is stronger. Furthermore, Business Intelligence systems use amplifies the effect of customer-side digital collaboration.
\end{abstract}

\section{Introduction}

\section{"Size can give you scale, but for innovation, speed is more critical" —Rakesh Kapoor, CEO of Reckitt Benckiser [1]}

Though innovation is considered to be the lifeblood of business in the 21 st century - practitioners unequivocally affirm that innovation alone is not enough. Instead, speed of innovation is as critical as innovation itself [1]. Business models of several successful firms such as Zara and Samsung, and leading firms of high-tech industries are exemplars of organizations that have leveraged speed of innovation as their key competitive advantage, which has resulted in sustained, enhanced firm performance [1]. Innovation is not a mere singular managerial decision but is a consequence of continuous business processes [2-4]. While firms may undertake extensive efforts to be innovative, it is the speed of innovation that can enhance the firm's chances of being successful. For example, when releasing new models, smartphone manufacturers tend to appeal to customers with innovative and unique designs. However, firms who are faster to innovate and release products to the market, such as Samsung or Apple among other leading smartphone makers, are able to obtain and sustain a greater competitive advantage. Samsung, with its lean and agile product development systems has released about 500 models to satisfy fast-changing customer needs since $2009^{1}$, and has shown a much faster speed of innovation than other competitors.

Similarly, speed of innovation plays an extremely vital role in sharing economy platforms. Platforms house a variety of participants, both upstream and downstream, to whom the speed of new services is extremely important. For instance, customers are essential actors who can aid the platform owner in identify emerging needs and ultimately co-create values with other consumers and platform participants [5]. Platforms that can quickly adapt to meet evolving customer needs will remain competitive and survive in the market [6]. For example, on the ride-sharing platform Uber, customers play an important role in creating value on the platform. In order to ensure

\footnotetext{
${ }^{1}$ https://en.wikipedia.org/wiki/Samsung_Galaxy
} 
customers continue using the platform, Uber has to be quick to innovate and meet customer needs in a timely manner.

While prior literature has been largely focused on investigating innovation [7], we aim to shine the light on the speed of innovation. In this study, we intend to identify the drivers of a firm's speed of innovation, particularly in recent dynamic business environments where key sources of innovation, including external and internal factors, change quickly. Among the factors, we focus on customer-side and supplier-side digital collaboration and use of business intelligence systems. Customers and suppliers are key external stakeholders of the firm that influence the creation of new products [8]. As customers are the end-users of the new product or service offerings, firms need to consider their needs while designing new products $[9$, 10]. Firms are able to effectively communicate with their customers through a variety of technologies such as Customer Relationship Management (CRM) systems [11]. Similarly, firms need to take into account supplier opinions when aiming to achieve agile and lean innovation and can communicate with suppliers using Supply Chain Management (SCM) systems [12]. Since customer and supplier relationships [or a (two-sided) customer relationship], and Information Systems (IS) such as SCM, CRM systems are critical components of platform businesses in the sharing economy, the findings of this study would be integral to the understanding of the sharing economy [13].

Accordingly, firms pursue innovation through two approaches: open innovation and closed innovation. Traditionally firms have followed an approach termed "closed innovation", wherein firms generate their own ideas. Firms then develop these ideas them, build them, market and distribute them, service and finance them, finance them, and support them on their own [14]. In recent years, an approach of open innovation has gained credence wherein firms collaborate with external stakeholders such as customers, suppliers, or competitors [14]. Open innovation has allowed for digitally enabled information flows to permeate porous organizational boundaries [15] and has transformed innovation processes by allowing suppliers and customers to contribute to innovation outcomes [2]. Thus, innovation is often the result of emergent, multiorganizational knowledge processes that are comprised of collaborative activities involving diverse stakeholders [16]. In summary, in the realm of open innovation, digitally enabled collaborative processes are now facilitating innovation $[8,17]$.

Given that open innovation is based upon collaborating with suppliers and customers, IT plays a critical role in the process. IT enables increased connectivity across the firm's partner network which creates avenues to collect data from its suppliers, customers, business partners [18]. Moreover, varied boundary-spanning collaborations enable the firm to generate insights from the data which can be leveraged in the innovation process. IT-enabled Business Intelligence (BI) Systems can help organizations in developing new or improved products and services, enriching organizational intelligence, targeting the right customers and even nurturing customer relationships $[19,20]$. Prior studies have identified the impact of customer side and supplier side factors on innovation $[9,10,21]$. The research that examines the effects of different types of firm-level IS and IT capabilities on innovation is also well-developed [4, 22-24]. However, few existing studies have, to our knowledge, examined the effects of IT and IS capabilities related to customer and supplier collaboration on innovation speed. Hence, in this study we pose the following question: Within this context of open innovation, how does the IT capability of a firm determine speed of innovation of the firm?

Within this broad question of understanding the role of IT on a firm's speed of innovation, we seek answers to the following specific avenues of investigation. Will digital collaboration with customers of a firm help the firm to speed innovation up? Will digital collaboration with suppliers of a firm help the firm to speed innovation up? Does a firm's use of BI systems catalyze innovation of the firm?

We hypothesize that collaboration with customers is more effective than collaboration with suppliers in order for firms to speedily innovate. This is because information obtained from customers is more relevant and pertinent for quick development of new products that exploit existing competencies, as compared to information from suppliers.

Furthermore, we hypothesize that a firm's digital collaboration with customers will have a greater effect on innovation speed when firms use Business Intelligence systems to manage and filter the data.

We test our hypotheses across a sample of 249 U.S. firms. Our econometric analyses yield strong support for our theory and hypotheses. We find corroborating evidence to suggest that while both customer-side and supplier-side digital collaboration are positively associated with innovation speed, the effect of customer-side digital collaboration on innovation speed is greater than the effect of supplierside digital collaboration. Furthermore, a firm's use of business intelligence systems increases the positive effect of customer-side digital collaboration on innovation speed but does not influence the 
relationship between supplier-side digital collaboration and innovation speed.

This research has significant theoretical and practical impact as it uncovers the drivers of innovation speed in the context of open innovation, which is a critical aspect of the sharing economy. Our findings enable firms to develop key competencies to withstand changes in their business environments and leverage IT optimally to fulfill their need for speed.

\section{Theoretical Background and Hypotheses Development}

\subsection{Innovation and Innovation Speed}

Innovation is the process by which organizations develop new products, services, business processes, or ideas, and forms one of main sources of competitive advantage for the firm [25]. In the sharing economy, innovation has become a more democratized process since individual actors participate and come together to create business value on the platform. Hence, the participation and involvement of customers is crucial for timely innovation in the sharing economy [26]. For example, Uber continues to develop new services and business models through open innovation. Uber understand different customer needs, suppliers, and regulations in different cities, and accordingly provides differentiated services for specific locations [27].

Innovation speed refers to the activities conducted in the time elapsed from the initial conceptualization of a new innovation to its final commercialization [28]. By improving their speed of innovation, firms can gain a competitive advantage by detecting and addressing consumer trends as they emerge, while simultaneously being able to improve quality and reduce costs [1]. The significance of innovation speed is highlighted in environments characterized by competitive intensity, technological and market dynamism, and low regulatory restrictiveness [28]. In order to survive and grow, especially in high clockspeed industries [29], it is imperative for firms to explore the underlying factors that predict and explain speed of innovations.

Prior literature has broadened the conversation around speed in innovation across different facets such as by studying the effects of the linear concept of time on organizations' cost and performance [28, 30, 31]. Speed of innovation can be positively or negatively affected by strategic-orientation factors as well as organizational-capability factors [32]. Furthermore, existing research suggests that speed of innovation has an influence on development costs, product quality, and ultimately project success. However, there remains a need to empirically examine the drivers of innovation speed in the context of open innovation which is integral to the sharing economy.

\subsection{Innovation and IT}

Innovation activities in the firm such as new product development and process design are enabled by IT [33]. Within the firm, IT can be leveraged to facilitate collaboration, teamwork and integration in order to drive innovation [34]. IT plays a key role to enable firms to conduct open innovation practices by enabling collaboration with external stakeholders [35]. This opens avenues for firms to access boundaryspanning knowledge sources [17], as well as conduct collaborative sensemaking activities from the collected information. IT promotes information processing and coordination across firms with their upstream and downstream partners. Past studies have captured how firms use IT to collaborate within their value chain in an open innovation fashion. For instance, previous studies have researched how manufacturing firms leveraged IT-based collaborations with their suppliers to conduct a revamp of their manufacturing process through automation.

Digital collaboration is enabled by implementing Information Systems such as Customer Relationship Management and Supply Chain Management systems. By doing so, firms are able to expand their knowledge sources by acquiring vital information from their value chain, and can thereby improve their innovation outcomes [4, 36, 37]. CRM systems provide channels to communicate with customers and, in recent years, social CRM technologies have enabled firms to engage with customers in collaborative conversations. This has allowed for enhanced customer relationships [38]. Digitally collected data through CRM systems, such as conversations recorded in customers service activities or consumer behavior data recorded when they search, browse, and purchase items, is useful for the firm to develop new products or services. By gaining new and diverse knowledge from its partners, the firm is more likely to successfully increase its innovation outcomes [39]. Digitally collaborating with partners can improve the firms' timing of releasing new products, forecasting demand and even estimating the volume of new product offerings to produce and release. For example, Uber can use data collected from its digital supply chain, such as information about drivers, to identify discrepancies in its business models and innovate its service offering.

Furthermore, IT-enabled Business Intelligence (BI) Systems elevate firms' innovation outcomes and overall can improve performance. Business 
intelligence systems use refers to using advanced data processing, analysis, management, and intelligence applications to obtain meaningful information to help an enterprise make decisions [40-42].

Business effectiveness lies in its ability to support decision making in an organization and provide decision makers with timely and relevant information. Organizations develop business intelligence capabilities to deal with the data that internal and external sources produce and leverage it to improve performance. Prior work on the use of business intelligence systems has examined the relationship between system use, competitive advantage, and performance. Prior research has suggested that business intelligence systems use improves management control systems and, thereby, augments performance measurement capabilities, which, in turn, provides a firm with a competitive advantage [42].

Similarly, studies have indicated that business intelligence systems use can also help organizations by improving their supply chain performance [43]. Further, use of business intelligence systems provides value to an organization via the organization's creating and using a business intelligence platform and business intelligence tools and end users' using such tools[42]. Organizations typically implement business intelligence systems to help them analyze data and support decision making. Accordingly, business intelligence systems can effectively help an organization improve its performance [44]. However, exploring how different business intelligence systems capabilities may help an organization increase its innovation speed remains a gap in the literature that we address in this study.

These business intelligence systems can help organizations in developing new or improved products and services, enriching organizational intelligence, targeting the right customers and even nurturing customer relationships $[19,20]$. Overall, a firm's use of business intelligence systems can be useful for coping with information overload or infobesity [45].

\subsection{Conceptual Framework and Hypotheses}

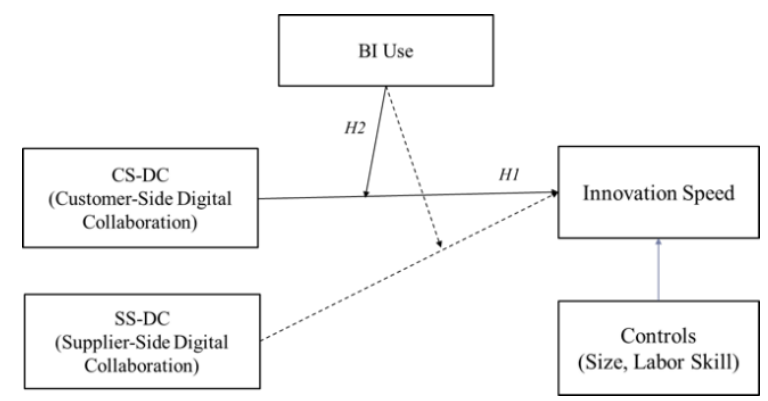

Figure 1. Research Model
Figure 1 presents our conceptual framework. We posit that firms' digital-collaboration activities with its customer network is relatively more important than its supplier network for timely launching its new products and services. By incorporating customer feedback, firms can gain a deep insight of market needs. Customers are in the best position to identify opportune times to introduce new products to the market. Customers are also able to help firms prioritize their new product development activities when faced with multiple needs. Thus, customer inputs are valuable in prioritizing enhancements to new products and services. Overall, digital collaborations with customers enables focal firms to gauge the pulse of the market and increase their pace of innovation to launch their new products [46].

For example, we illustrate this theoretical intuition through an example. SBI Life Insurance, is India's largest life insurance provider (after the Life Insurance Corporation of India). The channel partners of SBI Life Insurance leverage an IT system to capture information and feedback from customers. Consequently, this system is then used to collate, share and disseminate this information to one another. This customer facing digital collaboration enables SBI Life Insurance to imbibe customer insights into their new products and selling processes [47] at a fast pace, thereby helping the firm not only maintain but also grow its market share through new product and service offerings.

The firm's supply chain is another major source of information for a firm's business activities [48]. Information about suppliers, technologies, raw materials, and other inputs can be collected via SCM systems and this information is useful for firms to understand market demand and manage operations [49]. IT-enabled SCM systems of a firm enables the firm to unbundle information flows from physical flows, to have superior demand planning, and to streamline voluminous and complex work processes. The digitally enabled SCM influences firm performance, but it mainly affects operational excellence and revenue growth [36]. Thus, the effect of the supplier-side digital collaboration on innovation speed is rather indirect and smaller than the effect of the customer-side digital collaboration. Based on this theoretical logic, we put forward our first hypothesis:

H1: The effect of customer-side digital collaboration is greater than the effect of supplier-side digital collaboration on Innovation Speed. 
Deploying machine-centric filtering mechanisms such as Business Intelligence acts as an input additionality to the effect of customer-side digital collaboration on innovation speed [50]. In particular, business intelligence systems use does so by aiding in intelligently filtering the knowledge gathered from customers to improve the speed of innovation [51]. Business intelligence systems facilitate real time extraction of analyses and insights from customer inputs and feedback received through customer-side digital collaboration regarding their product market and service needs. This business intelligence systems use can instigate focused changes to innovation processes and outputs which are likely to be timelier than unfocussed ad broad-based efforts.

On the other hand, interacting with suppliers, though significant, does not reveal the beneficial information necessary for timely release to the market. Employing BI systems to filter information from suppliers will not have a significant impact on the speed of innovation. We put forward the second hypothesis:

H2: Business Intelligence Systems Use has a significant moderating effect on the relationship between customer-side digital collaboration and Innovation Speed and not on the relationship between supplier-side digital collaboration and Innovation speed.

\section{Method}

\subsection{Data}

This study uses survey data collected from a sample of 249 U.S. firms [17, 52]. Data collection was facilitated by a reputed market research firm. The survey respondents include presidents, vice presidents (VPs), chief executive officers (CEOs), chief financial officers (CFOs), chief information officers (CIOs), and other senior managers of the firms in the sample. Our data sample was drawn from a mix of eight industries - computer hardware \& services, electronics \& telecommunications, food \& beverages, chemicals \& pharmaceuticals, transport \& logistics, retail, business services, and energy \& mining. The distribution of firms' size, age and revenues in the sample is representative of the population of US firms from key industries.

Data was collected on the socio-technical efforts undertaken by the firms to facilitate innovation [53]. This includes extensive data on collaboration activities conducted by the firm with its business partners across the value chain [54]. We undertook extensive efforts during survey design and after data collection to ensure high reliability and validity to reduce the risk of common methods bias, including using differing scale anchors for different questions, randomizing question order across respondents, and employing the marker variable test.

We also validated the primary survey data with appropriate archival data sources (e.g., firm patent data in our survey was compared to U.S. Patent and Trademark Office (USPTO) data). Furthermore, the instrument was pilot tested in a smaller sample prior to large scale administration and was peer-reviewed by a panel of expert IS academics.

\subsection{Measures}

3.2.1. Innovation Speed. Our key dependent variable is Innovation Speed (INNOSP). We measure a firm's speed of innovation with three items. First if the given firm is typically the first to introduce new product/services in its industry. Second if the firm's speed of developing new products/services of the firm is higher than its rivals, and third if the given firm regularly upgraded existing products/services.

3.2.2. Customer-Side Digital Collaboration. In this analysis, our key predictor is customer-side digital collaboration. We capture Customer-side Digital Collaboration $(C S-D C)$ on a five-point scale $(1=$ No Collaboration; 5 = Very Extensive Collaboration) to measure the extent by which a firm digitally collaborated with its customers to obtain time-relevant information about new products/services in its line of business. Specifically, we collected information about a given firm's digital collaboration with customers through three items; to identify the timing of market needs for new products/services, to identify the best time to introduce new products/services to the market, and to regularly upgrade existing products/services.

3.2.3. Supplier-Side Digital Collaboration. In this analysis, a key comparative predictor is supplier-side digital collaboration. In this investigation, Supplierside Digital Collaboration ( $S S-D C$ ) was also captured on a five-point scale $(1=$ No Collaboration; $5=$ Very Extensive Collaboration) to measure the extent by which a firm digitally collaborated with its suppliers to obtain time-relevant information about new products/services in its line of business.

Specifically, we collected information about a given firm's digital collaboration with its supplier through three items; to identify the timing of market needs for new products/services, to identify the best time to introduce new products/services to the market, and to regularly upgrade existing products/services. 
3.2.4. Business Intelligence Systems Use (BISU). Along with digital collaboration, we captured the impact of using Business Intelligence Systems Use $(B I S U)$ as a way to filter information from the firms' partner network. The extent of use of BI systems is measured using two different seven-point scales, one each for capturing customer-side and supplier-side BI systems use. Table 1 summarizes mean, standard deviation, and reliability statistics. (Cronbach's alpha

Table 1. Descriptive statistics and reliability indices for constructs

\begin{tabular}{|l|c|c|c|}
\hline & Mean & $\begin{array}{l}\text { Standard } \\
\text { Deviation }\end{array}$ & $\begin{array}{l}\text { Cronbach's } \\
\text { Alpha }\end{array}$ \\
\hline INNOSP & 5.025 & 1.14 & 0.828 \\
\hline CS-DC & 3.345 & 0.992 & 0.891 \\
\hline SS-DC & 3.399 & 0.944 & 0.882 \\
\hline BISU & 4.731 & 1.261 & 0.861 \\
\hline
\end{tabular}

3.2.5. Control variables. The control variables included are Size and Labor Skill. A given firm's Size is measured by sales of the firm. Moreover, Labor Skill is measured by the three items - (1) the average percentage of employees primarily responsible for developing new products/services, (2) the average percentage of employees who are experts, and (3) the average training expenditure for human capital development as a percentage of total sale.

Two-stage Q-sorting is used to achieve high validity and reliability of our measurement items. Nine graduate students in business schools were hired to rate the questionnaire. The raters correctly classified $87 \%$ and $95 \%$ of items into intended variables, which suggests that the validity of our measurement is high enough. Cronbach's alphas of variables used in our research model are greater than 0.7 as shown in Table 1 , which suggests the reliability of our measurement is high enough.

\section{Analysis and Results}

Since our theory is concerned with testing both direct and moderation effects, we use a hierarchical regression modelling approach to test our hypotheses. Tests for over-dispersion in the distribution of the variable indicated no over-dispersion in the residuals. Nonetheless, we used standard errors that are robust to heteroskedasticity. We mean-centered the interaction terms to allay any concerns arising from multicollinearity. Nevertheless, as the highest variance inflation factors was less than 3.3, multicollinearity is not a major concern.
To test our hypotheses, we employ the specification in Equation 1. Table 2 shows the regression estimation results. To conserve space, we report only the results of the complete regression specifications. However, in our analysis we first test the direct effects separately and subsequently enter the moderation effects into our regression specifications.

Innovation Speed $=f(C S-D C, S S-D C, B I S U, C S-D C \times$ $B I S U$, SS-DC $\times B I S U$, controls)

Model 1 includes only CS-DC and SS-DC for independent variables, and Model 2 adds BISU to Model 1. Model 3 is our research model with which we test our hypotheses. The coefficient of $C S-D C(\beta=$ $0.380, p<0.01)$ is positive and significant, consistent with our expectation that customer-side digital collaboration has a favorable effect on Innovation Speed. H1 posited that Customer-Side Digital Collaboration has a stronger effect on Innovation Speed than Supplier-Side Digital Collaboration. Although the coefficient of SS-DC $(\beta=0.122, \mathrm{p}<$ 0.01 ) is significant and positive, it is significantly less than the coefficient of CS-DC (F-value in Wald test $=$ $9.56, \mathrm{p}<0.01)$. Hence, hypothesis 1 is supported.

Table 2. Results

\begin{tabular}{|c|c|c|c|}
\hline \multirow{2}{*}{$\begin{array}{l}\text { VARIABLES } \\
\text { (DP: INNSP) }\end{array}$} & \multicolumn{3}{|c|}{ Model } \\
\hline & 1 & 2 & 3 \\
\hline CS-DC & $\begin{array}{c}0.370 * * * \\
(0.066)\end{array}$ & $\begin{array}{c}0.402 * * * \\
(0.064)\end{array}$ & $\begin{array}{c}0.380 * * * \\
(0.064)\end{array}$ \\
\hline SS-DC & $\begin{array}{c}0.123 * * * \\
(0.062)\end{array}$ & $\begin{array}{c}0.140 * * * \\
(0.060)\end{array}$ & $\begin{array}{c}0.1221 * * \\
(0.060)\end{array}$ \\
\hline BISU & & $\begin{array}{c}0.269 * * * \\
(0.061)\end{array}$ & $\begin{array}{c}0.287 * * * \\
(0.061)\end{array}$ \\
\hline $\mathrm{CS}-\mathrm{DC} \times \mathrm{BISU}$ & & & $\begin{array}{l}0.135 * * * \\
(0.050)\end{array}$ \\
\hline $\mathrm{SS}-\mathrm{DC} \times \mathrm{BISU}$ & & & $\begin{array}{c}0.007 \\
(0.055)\end{array}$ \\
\hline Size & $\begin{array}{c}0.070 * * * \\
(0.031)\end{array}$ & $\begin{array}{c}0.074 * * * \\
(0.030)\end{array}$ & $\begin{array}{c}0.071 * * * \\
(0.030)\end{array}$ \\
\hline Labor Skill & $\begin{array}{l}0.270 * * * \\
(0.054)\end{array}$ & $\begin{array}{c}0.197 * * * \\
(0.055)\end{array}$ & $\begin{array}{c}0.176 * * * \\
(0.055)\end{array}$ \\
\hline $\begin{array}{l}\text { F- value in Wald test: } \\
\beta(\mathrm{CS}-\mathrm{DC})=\beta \text { (SS-DC) }\end{array}$ & $8.19 * * *$ & $9.94 * * *$ & $9.56 * * *$ \\
\hline $\begin{array}{l}\text { Observations } \\
\mathrm{R}^{2}\end{array}$ & 249 & 249 & $\begin{array}{c}249 \\
0383\end{array}$ \\
\hline $\begin{array}{l}\mathrm{R}^{2} \\
\text { Adjusted } \mathrm{R}^{2}\end{array}$ & $\begin{array}{l}0.314 \\
0.302\end{array}$ & $\begin{array}{l}0.365 \\
0.351\end{array}$ & $\begin{array}{l}0.383 \\
0.365\end{array}$ \\
\hline
\end{tabular}

$\mathrm{H} 2$ posited that Business Intelligence System Use has a significant moderating effect on the positive relationship between Customer-Side Digital Collaboration and Innovation Speed. On the other hand, Business Intelligence System Use does not have a significant moderating effect on the positive relationship between Supplier-Side Digital Collaboration and Innovation Speed. From Table 2, 
the coefficient of interaction of $C S-D C$ and $B I S U$ is positive and significant $(\beta=0.13, \mathrm{p}<0.01)$, and the coefficient of interaction of $S S-D C$ and $B I S U$ is not significant $(\mathrm{p}=\mathrm{ns})$. Hence, $\mathrm{H} 2$ is supported.

The control variables are largely consistent with expectations. The coefficient of Size is positive and significant, aligned with the notion that firms with greater scale are better equipped for speedy innovation. Additionally, Labor Skill is also positive and statistically significant. Hence, firms that invest in training their employees to develop more skilled human capital witness faster innovation.

\section{Discussion}

\subsection{Findings}

The purpose of this study was to explore the differentiated impact of collaborating with customers versus suppliers on the speed of innovation. Furthermore, we sought to examine the effect of implementing Business Intelligence systems in facilitating collaborations with external stakeholders. Our two findings confirm our initial expectations. First, while digitally collaborating with both suppliers and customers is helpful for a firm's speed of innovation, collaborating with customers is more favorable to bolster the rate at which firms develop new products. This implies that information gained from connecting with the firm's downstream network provides critical inputs for promptly meeting market needs. Second, we found that a firm's use of business intelligence systems increases the positive effect of collaborating with customers on speed of innovation. However, it does not influence the relationship between supplier-side collaboration and innovation speed. This highlights that a firm's digital collaboration with customers will be more effective when the firm uses business intelligence systems to filter and analyze the collected information [55].

\subsection{Theoretical Contributions}

This study offers extremely valuable contributions to the literature on innovation. We examine the relevant importance of the drivers of the speed of innovation. By leveraging their speed of innovation, firms can gain competitive advantages that can create sustained and enhanced overall performance.

Our key finding is that digitally collaborating with the firm's downstream network is more effective than digitally collaborating with the upstream network to improve the speed of developing new products. Furthermore, this effect is amplified in the presence of BI systems. These findings posit a hybrid model of innovation which brings together the technical mechanism that relies on Business Intelligence system use and a socio-technical mechanism that relies on digitally enabled collaboration with customers.

Our critical contribution is to the IT and Innovation literature. This literature has called for an examination of "how internal organizational and environmental conditions cause alternative mechanisms [to IT-enabled innovation] to be more or less binding", and how some "mechanisms are more effective than others and under what conditions" [56, 57]. We find that Business Intelligence Systems Use is one such condition which influences how IT-enabled innovation, especially in the context of open innovation in the sharing economy [58-60].

More generally, though there is significant work on IT and innovation [26, 61-63], this work tends to consider innovation outputs as the dependent variable of interest $[64,65]$. The speed of innovation is mostly an enigma for this research stream, with a notable exception [66]. Our study closely examines innovation speed and thus has started an important conversation on the timing of innovation.

\subsection{Managerial Implications}

We offer two key managerial implications. Managers are increasingly under pressure to leverage digital technologies such as business intelligence systems to reinvigorate their business models and conduct a digital transformation of their organizations $[56,67,68]$. However, it is important to acknowledge that Business Intelligence systems are not a panacea for all there is. While Business Intelligence systems present a machine-based solution to innovate, firms have and continue to benefit from other collaborationbased interactions with their partners which enable new combinations of knowledge.

Second, since open innovation has garnered significant attention due in part to the emergence of advanced digital platforms (e.g., crowdsourcing and open innovation challenges), managers tend to be excessively upbeat towards use of open innovation. We exhort managers not to disregard the speed of innovation as a key determinant of whom they collaborate with. This criterion should tailor their ITenabled innovation approach [69-71]. An implication for managers is that they need to periodically evaluate their firms' need for speed and take steps to orient their IT-enabled innovation approaches accordingly. This can involve deciding whether to collaborate with 
customers or suppliers depending upon the firm's exigencies and expediencies.

\section{Limitations and Conclusion}

We acknowledge limitations of our study. Our sample consists of small and medium enterprises from a single country (USA). Although focusing on a single country enhances internal reliability and avoids issues arising from cross-country heterogeneity, we can only theoretically claim but are unable to empirically demonstrate generalizability to other countries [72, 73]. Furthermore, this creates avenues for similar research in economies that are G.R.E.A.T (Growing, Rural, Eastern, Aspirational, Transitional) such as India [74-77].

In conclusion, in this study we examine the effects of customer-side and supplier-side digital collaboration on innovation speed and find customerside collaboration to be more effective. Furthermore, we investigate the moderating effect of a firm's use of business intelligence systems and found a positive effect of using Business Intelligence systems on customer-side digital collaboration on innovation speed. We discovered no influence of implementing Business Intelligence systems to filter information from supplier collaboration to ultimately improve innovation speed. Overall, our paper enlightens managers and academics on the role of IT capabilities in meeting firms' need for speed!

\section{References}

[1] M. Ringel, A. Taylor, and H. Zablit, "The Rising Need for Innovation Speed," The Boston Consulting Group, 2015.

[2] R. Garud, P. Tuertscher, and A. H. Van de Ven, "Perspectives on Innovation Processes," The Academy of Management Annals, vol. 7, no. 1, pp. 775-819, 2013/06/01 2013.

[3] Z. J. Acs and D. B. Audretsch, "Innovation in large and small firms: an empirical analysis," The American Economic Review, vol. 78, no. 4, pp. 678-690, 1988.

[4] L. Kleis, P. Chwelos, R. V. Ramirez, and I. Cockburn, "Information technology and intangible output: The impact of IT investment on innovation productivity," Information Systems Research, vol. 23, no. 1, pp. 4259, 2012.

[5] W. Nadeem, M. Juntunen, F. Shirazi, and N. Hajli, "Consumers' value co-creation in sharing economy: The role of social support, consumers' ethical perceptions and relationship quality," Technological Forecasting and Social Change, vol. 151, 2020.

[6] P. Karhade, A. Kathuria, O. Malik, and B. Konsynski, "Digital Platforms and Infobesity: A Research Agenda," in The Role of e-Business during the Time of Grand Challenges. WeB 2020. Lecture Notes in
Business Information Processing, A. Garimella, P. Karhade, A. Kathuria, X. Liu, J. Xu, and K. Zhao Eds. Cham: Springer 2021, pp. 67-74.

[7] H. Zhang, X. Zhang, and M. Song, "Does knowledge management enhance or impede innovation speed?," Journal of Knowledge Management, vol. 24, no. 6, 2020.

[8] M. Andrade Rojas, T. Saldanha, J. Khuntia, A. Kathuria, and W. F. Boh, "Overcoming Innovation Deficiencies in Mexico: Use of Open Innovation through IT and Closed Innovation through IT by Small and Medium Enterprises," in Hawaii International Conference on System Sciences, 2021, p. 617.

[9] K. C. Desouza et al., "Customer-driven innovation," Research-Technology Management, vol. 51, no. 3, pp. 35-44, 2008

[10] C. C. Bozarth, D. P. Warsing, B. B. Flynn, and E. J. Flynn, "The impact of supply chain complexity on manufacturing plant performance," Journal of operations management, vol. 27, no. 1, pp. 78-93, 2009.

[11] R. Reichwald, S. Seifert, and D. Walcher, "Customers as part of value webs: Towards a framework for webbed customer innovation tools," in Hawaii International Conference on System Sciences, 2004.

[12] J. Khuntia, A. Kathuria, M. G. Andrade-Rojas, T. Saldanha, and N. Celly, "How Foreign and Domestic Firms Differ in Leveraging IT-enabled Supply Chain Information Integration in BOP Markets: The Role of Supplier and Client Business Collaboration," Journal of the Association for Information Systems, vol. 22, no. 3, 2021.

[13] J. Q. Dong, P. Karhade, A. Rai, and S. X. Xu, "Information technology in innovation activity of the firm: Theory and synthesis," in European Conference on Information Systems, 2013.

[14] H. W. Chesbrough, Open innovation: The new imperative for creating and profiting from technology. Harvard Business Press, 2003.

[15] M. Bogers et al., "The open innovation research landscape: Established perspectives and emerging themes across different levels of analysis," Industry and Innovation, vol. 24, no. 1, pp. 8-40, 2017.

[16] M. L. Markus, A. Majchrzak, and L. Gasser, "A design theory for systems that support emergent knowledge processes," MIS quarterly, vol. 26, no. 3, pp. 179-212, 2002.

[17] P. Karhade and J. Q. Dong, "Innovation outcomes of digitally enabled collaborative problemistic search capability," MIS Quarterly, vol. 45, no. 2, pp. 693-718, 2021.

[18] M. Andrade Rojas, A. Kathuria, and B. Konsynski, "Competitive Brokerage: How Information Management Capability and Collaboration Networks Act as Substitutes," Journal of Management Information Systems, vol. Forthcoming, 2021.

[19] V.-H. Trieu, "Getting value from Business Intelligence systems: A review and research agenda," Decision Support Systems, vol. 93, pp. 111-124, 2017.

[20] D. D. Phan and D. R. Vogel, "A model of customer relationship management and business intelligence 
systems for catalogue and online retailers," Information \& management, vol. 47, no. 2, pp. 69-77, 2010.

[21] C. Valmohammadi, "Customer relationship management: Innovation and performance," International Journal of Innovation Science, vol. 9, no. 4, 2017.

[22] R. J. Lin, R. H. Chen, and K. K. S. Chiu, "Customer relationship management and innovation capability: an empirical study," industrial Management \& Data Systems, vol. 110, no. 1, 2010.

[23] V. Guerola-Navarro, H. Gil-Gomez, R. Oltra-Badenes, and J. Sendra-García, "Customer relationship management and its impact on innovation: A literature review," Journal of Business Research, vol. 129, pp. 8387, 2021.

[24] Y. Liao and Y. Li, "Complementarity effect of supply chain competencies on innovation capability," Business Process Management Journal, vol. 25, no. 6, pp. 1251$1272,2019$.

[25] G. R. Jones and C. W. L. Hill, Theory of Strategic Management, 10th ed. South-Western, 2013.

[26] K. Abhari, E. J. Davidson, and B. Xiao, "Collaborative innovation in the sharing economy," Internet Research, vol. 29, no. 5, 2019.

[27] J. J. Yun, X. Zhao, J. Wu, J. C. Yi, K. Park, and W. Jung, "Business model, open innovation, and sustainability in car sharing industry - Comparing three economies," Sustainability, vol. 12, no. 5, p. 1883 , 2020.

[28] E. H. Kessler and A. K. Chakrabarti, "Innovation speed: A conceptual model of context, antecedents, and outcomes," Academy of management review, vol. 21, no. 4, pp. 1143-1191, 1996.

[29] H. Mendelson and R. R. Pillai, "Industry clockspeed: Measurement and operational implications," Manufacturing \& service operations management, vol. 1, no. 1, pp. 1-20, 1999.

[30] K. M. Eisenhardt, "CMR Classics: Speed and Strategic Choice: How Managers Accelerate Decision Making," California management review, vol. 50, no. 2, pp. 102116, 2008.

[31] D. E. Vinton, "A new look at time, speed, and the manager," Academy of Management Perspectives, vol. 6, no. 4, pp. 7-16, 1992.

[32] T. W. Jackson and P. Farzaneh, "Theory-based model of factors affecting information overload," International Journal of Information Management, vol. 32, no. 6, pp. 523-532, 2012.

[33] P. P. Karhade and D. John Qi, "Innovation Outcomes of Digitally Enabled Collaborative Problemistic Search Capability," MIS Quarterly, vol. 45, no. 2, 2021.

[34] S. Nambisan, "Information systems as a reference discipline for new product development," MIS Quarterly, vol. 27, no. 1, pp. 1-18, 2003.

[35] T. Saldanha, S. Mithas, and M. Krishnan, "Leveraging Customer Involvement for Fueling Innovation: The Role of Relational and Analytical Information Processing Capabilities," MIS Quarterly, vol. 41, no. 1, pp. 267-286, 2017.

[36] A. Rai, R. Patnayakuni, and N. Seth, "Firm performance impacts of digitally enabled supply chain integration capabilities," MIS quarterly, vol. 30, no. 2, pp. 225-246, 2006.

[37] J. Gómez, I. Salazar, and P. Vargas, "Does information technology improve open innovation performance? An Examination of Manufacturers in Spain," Information Systems Research, vol. 28, no. 3, pp. 661-675, 2017.

[38] K. J. Trainor, J. M. Andzulis, A. Rapp, and R. Agnihotri, "Social media technology usage and customer relationship performance: A capabilitiesbased examination of social CRM," Journal of business research, vol. 67, no. 6, pp. 1201-1208, 2014.

[39] C. A. Un, A. Cuervo-Cazurra, and K. Asakawa, "R\&D collaborations and product innovation," Journal of Product Innovation Management, vol. 27, no. 5, pp. 673-689, 2010.

[40] T. Ramakrishnan, A. Kathuria, and J. Khuntia, "Business Analytics Capability and Supply Chain Management," Americas Conference on Information Systems, 2018.

[41] T. Ramakrishnan, J. Khuntia, A. Kathuria, and T. J. Saldanha, "Business intelligence capabilities," in Analytics and Data Science: Springer, 2018, pp. 15-27.

[42] T. Ramakrishnan, J. Khuntia, A. Kathuria, and T. J. Saldanha, "An Integrated Model of Business Intelligence \& Analytics Capabilities and Organizational Performance," Communications of the Association for Information Systems, vol. 46, no. 1, p. 31, 2020.

[43] T. Ramakrishnan, A. Kathuria, and T. J. Saldanha, "Business Intelligence and Analytics (BI\&A) Capabilities in Healthcare," in Theory and Practice of Business Intelligence in Healthcare: IGI Global, 2020, pp. 1-17.

[44] S. Mithas, N. Ramasubbu, and V. Sambamurthy, "How Information Management Capability Influences Firm Performance," MIS Quarterly, vol. 35, pp. 237-256, 2011.

[45] H. Chen, R. H. Chiang, and V. C. Storey, "Business intelligence and analytics: From big data to big impact," MIS Quarterly, vol. 36, no. 4, pp. 1165-1188, 2012.

[46] J. Q. Dong, J. He, and P. Karhade, "The Penrose effect in resource investment for innovation: Evidence from information technology and human capital," in European Conference on Information Systems, 2013.

[47] J. Khuntia, A. Kathuria, T. J. Saldanha, and B. R. Konsynski, "Benefits of IT-enabled flexibilities for foreign versus local firms in emerging economies," Journal of management information systems, vol. 36, no. 3, pp. 855-892, 2019.

[48] S. Dewan and F. Ren, "Information Technology and Firm Boundaries: Impact on Firm Risk and Return Performance," Information Systems Research, vol. 22, no. 2, pp. 369-388, 2011.

[49] R. L. Priem and M. Swink, "A Demand-side Perspective on Supply Chain Management," Journal of Supply Chain Management, vol. 48, no. 2, pp. 7-13, 2012.

[50] K. M. Sutcliffe and K. E. Weick, "Information overload revisited," in The Oxford handbook of organizational decision making: Oxford University Press, 2009. 
[51] X. Ning, J. Khuntia, A. Kathuria, and P. Karhade, "Ownership and Management Control Effects on IT Investments: A Study of Indian Family Firms," in International Conference on Information Systems, 2020.

[52] O. Malik, P. Karhade, and A. Kathuria, "How Technology Use Drives Infobesity: An In-Depth Look at ERP Systems," in Pacific Asia Conference on Information Systems, 2021

[53] J. Q. Dong, P. Karhade, A. Rai, and S. X. Xu, "Dynamic adjustment of information technology, corporate governance, and firm profitability," in European Conference on Information Systems 2013.

[54] H.-T. Wagner, D. Beimborn, and T. Weitzel, "How Social Capital Among Information Technology and Business Units Drives Operational Alignment and IT Business Value," Journal of Management Information Systems, vol. 31, no. 1, pp. 241-272, 2014.

[55] T. Saldanha, A. Kathuria, J. Khuntia, B. Konsynski, and M. Rojas, "Leveraging Digitalization of Services for Performance: Evidence from the Credit Union Industry," in International Conference on Information Systems, 2017.

[56] R. Kohli and N. P. Melville, "Digital innovation: A review and synthesis," Information Systems Journal, vol. 29, no. 1, pp. 200-223, 2019.

[57] C. Velu, M. Barrett, R. Kohli, and T. Salge, Thriving in open innovation ecosystems: Toward a collaborative market orientation. Judge Business School, University of Cambridge, 2010.

[58] N. Jia, A. Rai, and S. X. Xu, "Reducing Capital Market Anomaly: The Role of Information Technology Using an Information Uncertainty Lens," Management Science, vol. 66, no. 2, pp. 979-1001, 2020.

[59] A. Kathuria, T. Saldanha, J. Khuntia, M. Andrade Rojas, S. Mithas, and H. Hah, "Inferring Supplier Quality in the Gig Economy: The Effectiveness of Signals in Freelance Job Markets," in Hawaii International Conference on System Sciences, 2021.

[60] A. Kathuria, T. Saldanha, J. Khuntia, M. G. Andrade Rojas, and H. Hah, "Strategic Intent, Contract Duration, and Performance: Evidence from Micro-Outsourcing," in International Conference on Information Systems, 2015.

[61] K. Abhari, E. Davidson, and B. S. Xiao, "Taking open innovation to the next level: a conceptual model of social product development (SPD)," in Americas Conference on Information Systems, 2016.

[62] K. Abhari, E. J. Davidson, and B. Xiao, "Co-innovation platform affordances," Industrial Management \& Data Systems, vol. 117, no. 5, 2017.

[63] K. Abhari, E. J. Davidson, and B. Xiao, "Measuring the perceived functional affordances of collaborative innovation networks in social product development," in Hawaii International Conference on System Sciences, 2016.

[64] T. Saldanha, A. Kathuria, J. Khuntia, and B. Konsynski, "Ghosts in the Machine: How Marketing and Human Capital Investments Enhance Customer Growth when Innovative Services Leverage Self-Service Technologies," Information Systems Research, 2021.
[65] T. J. V. Saldanha, A. Sahaym, S. Mithas, M. G. Andrade-Rojas, A. Kathuria, and H.-H. Lee, "Turning Liabilities of Global Operations into Assets: ITEnabled Social Integration Capacity and Exploratory Innovation," Information Systems Research, vol. 31, no. 2, pp. 361-382, 2020.

[66] P. Tambe, L. M. Hitt, and E. Brynjolfsson, "The extroverted firm: How external information practices affect innovation and productivity," Management Science, vol. 58, no. 5, pp. 843-859, 2012.

[67] R. Browder, H. Koch, A. Long, and J. Hernandez, "Learning to Innovate with Big Data Analytics in InterOrganizational Relationships," Academy of Management Discoveries, 2020.

[68] H. A. Simon, K. W. Deutsch, and M. Shubik, "Designing organizations for an information-rich world," in Computers, communications, and the public interest, ed, 1971, pp. 37--72.

[69] J. Q. Dong, P. P. Karhade, A. Rai, and S. X. Xu, "How Firms Make Information Technology Investment Decisions: Toward a Behavioral Agency Theory," Journal of Management Information Systems, vol. 38, no. 1, pp. 29-58, 2021.

[70] P. Karhade, M. J. Shaw, and R. Subramanyam, "Patterns in information systems portfolio prioritization," Mis Quarterly, vol. 39, no. 2, pp. 413434, 2015.

[71] P. P. Karhade, M. J. Shaw, and R. Subramanyam, "Patterns in strategic IS planning decisions: An inductive approach," in Americas Conference on Information Systems, 2009, p. 397.

[72] B. Kogut and H. Singh, "The effect of national culture on the choice of entry mode," Journal of International Business Studies, vol. 19, no. 3, pp. 411-432, 1988.

[73] S. Mithas, J. Whitaker, and A. Tafti, "Information Technology, Revenues, and Profits: Exploring the Role of Foreign and Domestic Operations," Information Systems Research, vol. 28, no. 2, pp. 430-444, 2017.

[74] A. Dasgupta, P. Karhade, A. Kathuria, and B. Konsynski, "Holding Space for Voices that Do Not Speak: Design Reform of Rating Systems for Platforms in GREAT Economies," in Hawaii International Conference on System Sciences, 2021.

[75] P. Karhade and A. Kathuria, "Missing Impact of Ratings on Platform Participation in India: A Call for Research in GREAT Domains," Communications of the Association for Information Systems, vol. 47, no. 1, p. 19, 2020.

[76] A. Kathuria, J. Khuntia, P. Karhade, and X. Ning, "Don't Ever Take Sides with Anyone Against the Family: Family Ownership and Information Management," in Americas Conference on Information Systems, 2019.

[77] X. Ning, J. Khuntia, A. Kathuria, and P. Karhade, "Information Technology Investment, Environmental Hostility, and Firm Performance: The Roles of Family Ownership in an Emerging Economy," in Hawaii International Conference on System Sciences, 2020. 